\title{
Plenary Speaker Gargini to Address Materials and the Semiconductor Industry
}

Paolo Gargini, director of Technology Strategy for Intel Corporation, will present his Plenary talk, "Impact of New Materials on the Semiconductor Industry," at the 1999 MRS Spring Meeting in San Francisco. The plenary will be held on Monday, April 5, 6:00 p.m. in Salon 7 at the Marriott Hotel.

Since joining Intel in 1978, Gargini has conducted studies on contact electromigration and failure mechanisms of advanced metal-oxide-semiconductor (MOS) structures in the area of process reliability. He has also been responsible for developing the building blocks of HMOS III and CHMOS III technologies used in the 1980s, and coordinating the development of the process modules common to memory and logic technologies.

After receiving a doctorate in electrical

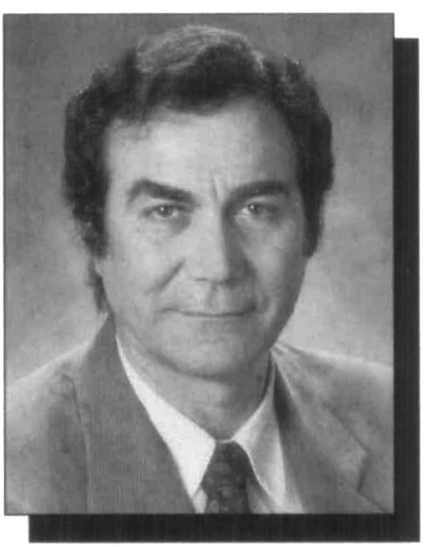

engineering in 1970 and a doctorate in physics in 1975 from the Universita di Bologna, Italy, Gargini did research at LAMEL in Bologna, Stanford Electronics
Laboratory, and Fairchild Camera and Instrument Research and Development. He has authored a number of papers on complementary metal oxide semiconductor, charge coupled device, and thin film technologies, and holds patents on EPROM and interconnection technologies. Gargini has been a keynote speaker at numerous conferences and universities throughout the United States, Europe, and Japan, and he has been distinguished as an Intel Fellow.

Since 1993, Gargini has been an active member of the Executive Technical Advisory Board of Sematech. He is also Chair of the Executive Steering Council for the International Sematech, and Chair of the International Technology Roadmap for Semiconductors.

\section{MRS Invites Nominations for the Von Hippel Award, Turnbull Lectureship, and MRS Medal}

The Materials Research Society is seeking nominations for the Von Hippel Award, the Turnbull Lectureship, and the MRS Medal. The deadline for nominations is June 1, 1999. These awards will be presented at the 1999 MRS Fall Meeting, November 29-December 3, in Boston.

The MRS Awards Program recognizes outstanding contributors to the progress of materials research. Nomination forms and details about eligibility and nomination criteria are available from Amy Williams, Materials Research Society, 506 Keystone Drive, Warrendale, PA 150867573; phone 724-779-3004 ext. 102; fax 724779-8313. Further information about each award can also be obtained from the MRS website at http: / / www.mrs.org/.

\section{Von Hippel Award Acknowledges Outstanding Interdisciplinary Work in Materials Research}

The Von Hippel Award, first presented to Arthur R. von Hippel whose interdisciplinary and pioneering research typified the spirit of the award, is the Materials
Research Society's highest honor. The recipient is recognized for brilliance and originality combined with vision that transcends the boundaries of conventional scientific disciplines. The Award includes a $\$ 10,000$ cash prize, honorary membership in MRS, and a unique trophy-a mounted ruby laser crystal symbolizing the many-faceted nature of materials research.

Selection of the recipient is determined by a vote of the MRS Council. The recipient will be invited to speak at the Awards Ceremony.

\section{Turnbull Lectureship Honors Career of an Outstanding} Researcher and Communicator

The David Turnbull Lectureship recognizes the career of a scientist who has made outstanding contributions to understanding materials phenomena and properties through research, writing, and lecturing, as exemplified by the life work of David Turnbull. While honoring the accomplishments of the recipient, the Turnbull Lectureship is intended to sup- port and enrich the materials research community.

The recipient will give a technical lecture of broad appeal at a designated session of the 1999 MRS Fall Meeting. The Turnbull Lecturer will receive a $\$ 5,000$ honorarium and a citation plaque, along with travel expenses paid to enable the recipient to address MRS Sections and University Chapters, and/or participate in the production of a video version of the lecture.

\section{MRS Medal Recognizes Recent Discovery or Advancement in Materials Science}

The MRS Medal offers public and professional recognition of an exceptional recent achievement in materials research. A medal will be awarded for a specific outstanding recent discovery or advancement which is expected to have a major impact on the progress of any materialsrelated field.

The award consists of a $\$ 3,000$ cash prize, an engraved and mounted medal, and a citation certificate. 